\title{
LA IGLESIA DE BASE CHILENA VISTA CON OJOS DE MUJER. PERSPECTIVA HISTÓRICA A TRAVES DEL TESTIMONIO DE FRANCISCA MORALES.
}

\author{
David FERNANDEZ FERNANDEZ \\ Universidad de Cádiz
}

$\underline{R E S U M E N}$

Visión de los movimientos cristianos de base de la Iglesia chilena a través de la experiencia directa de Francisca Morales.

Palabras clave: Chile, siglo XX. Iglesia. Historia oral.

\section{SUMMARY}

Vision of the christian mouvements in the chilean church through the direct experience of Francisca Morales.

Keywords: Chile, XXth century. Church. Oral History.

Mirar la historia de la Iglesia católica con ojos de mujer es alumbrar una historia llena de exclusión respecto al sexo femenino. Siendo mayoría en la Iglesia, siguen siendo los grandes sujetos anónimos de una institución secularmente machista. El testimonio oral de Francisca Morales, Panchita, nos lleva hasta la intrahistoria del catolicismo de base chileno, nos permite recuperar la historia de "las olvidadas". Una historia que no se cuece al calor del poder, sino al de la cotidianidad llena de vida de las que no lo tienen, de las que, como dice una canción de Víctor Jara, lo único que tienen son sus manos: para amar y sobrevivir, para buscar su propia dignidad y luchar por la vida de todas y de todos.

El testimonio de Francisca Morales nos aporta, por un lado, datos que aluden a su propia persona, a su biografía, y, por otra parte, acontecimientos que son relatados desde el lugar desde el que le tocó, o mejor dicho, desde el que optó vivirlos. Tanto unos como otros nos permiten reconstruir una historia de la Iglesia de base chilena desde el punto de vista de la mujer. Vamos a empezar recuperando la identidad de Francisca Morales como sujeto activo de esa historia, para luego pasar a la profundización de algunos de los hechos que son fundamentales para la comprensión de la historia del cristianismo de base chileno desde el Concilio Vaticano :II hasta la actualidad, siempre a través del testimonio oral de la informante. 
La entrevista se realizó el 4 de diciembre de 1993 en la parroquia de San Pedro y San Pablo, en Santiago de Chile. A Francisca Morales la había conocido en la eucaristía que Ronaldo Muñoz, sacerdote de los Sagrados Corazones y teólogo de la liberación, celebra cada sábado con la comunidad de la población Yungay en la capilla Nuestra Señora de Guadalupe. Tal como habíamos quedado citados nos vimos en el despacho parroquial y grabamos un testimonio que duró algo más de una hora. Como hice a lo largo de todas los testimonios que grabé en Chile, una vez planteado el tema que me interesaba, en este caso la Iglesia católica chilena desde el Concilio hasta la "transición", dejába al informante hablar espontáneamente sin dirigir constantemente su discurso. Con ello conseguía que el informante volcara sobre la grabadora su propio punto de vista con total libertad, pudiendo incidir más en aquello que a él le pareciera importante, sin estar continuamente mediatizado por mis preguntas, con lo que, además, conseguía abrir camino hacia hechos que a lo mejor yo no conocía o que en principio no me habían llamado la atención y que, sin embargo, adquirían dimensión al ser relatados por sus protagonistas. En el fondo, la técnica consistía en escuchar dejándome guiar por los testimonios, siempre contrastados con otras fuentes, y sin pretender enlatar las palabras de los informantes en unos esquemas previos, entre otras razones porque la oralidad suele hacer saltar los a priori construidos desde el discurso escrito al permitirnos llegar hasta los excluidos, hasta los que no tienen poder para dejar constancia escrita de sus vidas, por lo que, evidentemente, cambiado el lugar desde el que se habla, suelen cambiar los matices y las prioridades. En este sentido el testimonio de Francisca Morales es denso y rico.

Francisca es religiosa de la Congregación del Amor Misericordioso. Como tal vivió toda la renovación de la vida religiosa que trajo consigo el Concilio y formó parte de las religiosas "de avanzada" que se insertaron en sectores populares en los que todavía no había presencia oficial de Iglesia, desempeñando labores pastorales "de frontera". Estuvo un año viviendo en un sector popular sin tareas evangelizadoras, lo que le permitió descubrir la mentalidad y el estilo de vida de los más "pobres" a partir de la convivencia con la gente. La experiencia fue impactante para ella y marcó su compromiso desde entonces. Perteneció al movimiento Cristianos por el Socialismo en la época de la Unidad Popular y estuvo cercana a los eventos convocados por la Coordinadora de Comunidades Cristianas Populares durante la dictadura. La opción de Francisca Morales por la liberación fue una opción que se concretó en una enorme cercanía al mundo de los oprimidos y en un buscar instrumentos que permitieran la construcción de un mundo sin opresión ni exclusión. Además, ha pasado por diferentes cargos de responsabilidad en su Congregación y en el CONFERRE (Conferencia de Religiosos de Chile). Tiene estudios de Teología, pero no terminó la titulación porque como ella misma dice: 
"... en realidad no me interesaba sacar el título ni nada, porque para mi lo más importante es estar metida en el mundo de los pobres que seguir una carrera de corte académico. Me interesaba saber para servir mejor más que para meterme en el quehacer teoíógico. Pero la verdad es que uno va haciendo teología al reflexionar sobre la propia vida y la vida de la Iglesia de base, y va articulando cosas casi sin darse cuenta, que es una manera distinta de hacer teología". ${ }^{1}$

Y realmente llevó a la práctica lo que acaba de decirnos. Durante un tiempo formó parte de ESTEPA (Equipo de Estudios Teológicos y Pastorales), haciendo un interesante aporte desde la perspectiva de la mujer en un quehacer teológico excesivamente monopolizado por hombres, aunque su labor fue más práctica que teórica: a ella le correspondía el trato con la gente, haciendo uso de su preparación pedagógica. Pero finalmente, lo dejó porque quería estar más metida en la vida de la Iglesia de base (lo que indirectamente nos está diciendo que el dedicarse a la "reflexión teológica" de una forma más sistemática, podríamos decir profesional, lleva el riesgo del alejamiento de la vida si uno no anda bien despabilado). Francisca Morales es realmente un testimonio vivo de compromiso con los más "pobres", mujeres y hombres, y un ejemplo de cómo los agentes pastorales son convertidos al convivir con la gente de los sectores populares. Vistos 'estos trazos de la identidad de la informante, vamos ahora a seguir su testimonio para analizar la historia de la Iglesia de base en distintos momentos.

\section{LOS AÑOS SESENTA: COMUNIDADES DE BASE E INSERCION DE LOS AGENTES PASTORALES EN LOS SECTORES POPULARES.}

Un primer momento sería la decada de los sesenta. En estos años varios hechos van a orientar el rumbo de la Iglesia católica. En la primera mitad de los sesenta, por un lado, el Concilio Vaticano II (1962-1965), que va a producir un "aggiornamento" ("puesta al día") de la Iglesia, tomando especial relevancia el diálogo con el Mundo, la urgencia de mostrar un rostro de la Iglesia que fuera más humanista y evangélico frente al legalismo existente, la articulación del concepto "Iglesia pueblo de Dios" en la historia y la revalorización del papel de los laicos en la misma, entre otras propuestas. Todo esto unido a las palabras de Juan XXIII en las que proclamaba que la Iglesia debía ser la "Iglesia de los pobres". Si a nivel mundial fue el Concilio, a nivel latinoamericano vemos un contexto marcado por el debate entre los diferentes discursos de la "revolución". Son los años de la utopía revolucionaria, utopía empujada por el ejemplo de la revolución cubana y por la necesidad de hacer algo urgente contra la situación de miseria y exclusión que se vivía en el continente. $Y$, junto a ello, en Chile, la realización de la Misión General de Santiago (1963), que fue un intento de acercar la Iglesia a los distintos sectores de esa macrociudad que crecía de manera desbordante; intento del que nacieron 
numerosas comunidades de base en los sectores populares. ${ }^{2}$ Así pues, "aggiornamento", "revolución" y "Misión General", son tres de las claves a tener en cuenta para entender el rumbo que tomará la Iglesia chilena en la segunda mitad de los sesenta. ¿Por qué? Porque una de las consecuencias más inmediatas del contexto sociopolítico prerrevolucionario que se vivía y de la apertura hacia el Mundo de una Iglesia más preocupada por las cuestiones sociales, fue el proceso a través del cual los agentes pastorales (religiosas, religiosos y sacerdotes) marchan a las poblaciones marginales para llevarle a los sectores populares una Iglesia más cercana a la vida. Proceso del que surgirá, al encontrarse cara a cara el sacerdote y/o la religiosa con la realidad de miseria y opresión que padecía el pueblo, un nuevo modelo de Iglesia que tanto va a marcar la historia de la Iglesia católica chilena, y latinoamericana, desde la segunda mitad de los años sesenta hasta nuestros días.

Francisca Morales $^{3}$ nos cuenta cómo vivió ese éxodo y todo el proceso de inserción en una población de la periferia. La Misión General sirvió para descubrir el potencial evangelizador de las religiosas: "estando el Concilio en proceso se hizo aquí en Santiago la Gran Misión, Misión General, y eso permitió descubrir el potencial evangelizador de las religiosas de una manera sorprendente". Hasta ese momento el rol de las religiosas había estado totalmente subordinado al poder de los sacerdotes. Las religiosas eran meras auxiliares de éstos, que solían acaparar las actividades pastorales más interesantes, quedando para las religiosas otras tareas que el clero no quería realizar. Pero al descubrirse el potencial de las religiosas éstas empezarán a introducirse de lleno en la pastoral directa con responsabilidades que anteriormente eran exclusivas de los sacerdotes: "manteniamos todos los libros parroquiales dependientes de la parroquia; podiamos bautizar, casar, predicar y, bueno, asumir las liturgias". Además formaban a los laicos.

Y junto a la importancia de la Misión General, la del Concilio, a raíz del cual surgió la renovación de la Congregación del Amor Misericordioso que hizo posible la marcha de las religiosas hacia las poblaciones periféricas donde no había ninguna presencia de la Iglesia oficial:

"... poco después del Concilio, en el año 65 terminó el Concilio, en el 67 ya hicimos nuestro primer Capítulo de renovación general, y esto porque el cardenal Silva conoció en Europa al padre Perlton, que trabajó con Suenens en el primer Capítulo de renovación de vida religiosa en Europa, entonces, como él se iba a venir a Chile, le dijo que a él le gustaria que estas religiosas que él las consideraba auxiliares pastorales, porque somos una Congregación diocesana, que estas religiosas hicieran su Capitulo de renovación para insertarse más en la vida de la Iglesia. Entonces, nos convocó, nos presentó al padre Perlton, en el año 66, y a partir de ese momento nosotros nos envolvimos en todo ese proceso de madurar, o de 
conocer un poco más el texto del Concilio y empezar un diálogo entre nosotras de búsqueda, ¿verdad?. Habia muchas cosas en las que el Concilio nos confirmaba en nuestras propias experiencias de búsqueda y también otras cosas que eran una novedad. Pero el espíritu, como somos una Congregación chica, de las hermanas fue bastante abierto y generoso e iniciamos un Capítulo de renovación que quedó abierto en primera instancia el año ya 67. Y ese año el Cardenal Silva nos habia pedido que nosotras abriéramos casas, viviendas en medio de la gente, en sectores del Santiago más marginal, donde no habia sacerdotes ni presencia oficial de Iglesia. Entonces, que él nos ponía la casa para facilitar la ida y que nosotras nos insertáramos...".

A pesar de que se suponía que su congregación conocía el mundo de los pobres, puesto que se dedicaba específicamente a él, sobre todo a la mujer pobre, Francisca Morales reconoce el impacto que supuso para ellas empezar a vivir entre ellos. Experiencia que tuvieron en la zona Oeste de Santiago, donde Fernando Ariztía, obispo auxiliar de la misma, las había acogido:

"Nos quedamos con don Fernando porque nos parecia que (era) el que mejor entendía este caminar de la vida religiosa en renovación y, también, que valoraba la presencia de las religiosas, no sólo el quehacer de las religiosas; valoraba a las hermanas, se preocupaba por ellas, en fin, nos pareció un obispo muy cercano, muy pobre, muy sencillo, viviendo él también en una casita de población en medio de los pobres".

Fernando Ariztía les permitió estar un año en la población sin tareas pastorales, tan sólo viviendo con la gente, haciéndose al lugar, metiéndose en el tejido popular. Las religiosas descubren que no es lo mismo "atender" a los pobres que vivir con ellos: su congregación tenía experiencia de trabajo con madres solteras, :con niñitas vagas, con niñitas de prostitución"; atendían la hospedería del "Hogar de Cristo"4, "escuelitas parroquiales de pueblecitos chicos"... pero "otra cosa es vivir entre la gente". Ese año fue un tiempo de tomarle el pulso a la vida de la población: "conocer la mentalidad, el estilo de la vida de la gente". Y un tiempo para descubrir las organizaciones propias del pueblo: "era la época de la promoción popular y habia mucho movimiento social. Había centros de madres, centros de jóvenes...". Y no sólo descubrirlas, sino introducirse en ellas, ya que ella y sus hermanas de congregación habían optado por vivir como pobladoras en todos los aspectos: "las hermanas partimos a vivir, a formar parte de estas agrupaciones como una vecina más, sabiendo la gente que éramos religiosas y todo, pero metiéndonos así". Además, mostraron una gran sensibilidad para captar por dónde iba el pueblo en sus inquietudes cotidianas. Para ello visitaban a las familias, dialogaban con ellas, se mostraban cercanas, lo que no resultaba difícil teniendo en cuenta 
que se estaban implicando en la vida de la población, que no se limitaban a venir desde fuera. Ahora bien, ¿cómo aceptaba la gente a las religiosas?. La experiencia de Francisca Morales es la de una cálida acogida: "el pueblo chileno es muy cariñoso, es muy acogedor". Es más, la gente aceptaba sin problemas que fueran monjas sin hábito. El hábito era como una barrera sicológica que las alejaba de las personas. Sobre este aspecto hace alusión a una anécdota que les ocurrió en la parroquia de San Pedro y San Pablo, a donde fueron a misionar invitadas por Esteban Gumucio, su párroco, durante la Gran Misión. Ellas iban con hábito todavía y "la cabrería chica andaba detrás (gritando): ¡la curita!, ila curita!... o gritando: ¡mamá!, ¡mamá!, ¡ven a ver a la virgencita!".

Por otra parte hay que señalar que las religiosas se insertaban mejor que los curas en la vida del pueblo, tenían más llegada a los hogares: si "te encuentras en una casa a la señora pelando papas, te pones a pelar papas con ella; si la encuentras cosiendo, la ayudas a pegar botones; o con los niños... en fin, mientras uno conversa se va metiendo en la vida". Les resultaba más fácil que a los sacerdotes implicarse en las pequeñas actividades de lo cotidiano. En este sentido, Sergio Silva elogia el papel de las congregaciones de religiosas en la Iglesia chilena, religiosas que se meten en el mundo popular "con una abnegación, con una capacidad de ternura, de entrega, de compartir la vida, pero intensamente; eso que llaman la inserción ellas la realizan, no sé, las mujeres tienen algo que nosotros no tenemos".

El ideal de estas religiosas era ir formando a los laicos para que éstos asumieran responsabilidades dentro de la Iglesia, y "no ponernos nosotras a reemplazar al curita y hacerlo todo en torno a nosotras sin hacer que la gente creciera" . Por eso, siguiendo las directrices de Fernando Ariztía, empezaron a formar comunidades, "pequeños grupos en las casas de los vecinos", y a dinamizar una catequesis familiar donde se fueran incorporando parejas como guías y no sólo mujeres, puesto que el rostro de quienes construían la Iglesia en las poblaciones era mayoritariamente femenino: "las mujeres fueron asumiendo la catequesis de una manera realmente extraordinaria". Era una Iglesia más femenina a pesar del machismo estructural del orden eclesiástico: las hermanas eran las formadoras y las catequistas eran mujeres. Los hombres se incorporaban sobre todo a los grupos comunitarios y allí "casi siempre asumian puestos de dirección, porque como tienen el hábito..." (claro ejemplo del machismo del que hablábamos), pero poco a poco las mujeres fueron asumiendo "roles de conducción pastoral en igualdad de condiciones".

De esta manera las comunidades de base se convertían en una expresión de la "encarnación" de la Iglesia según la lógica de los pobladores y pobladoras. Aunque su origen hubiera sido una decisión de la jerarquía para descentralizar las parroquias, las comunidades fueron más allá de ser simplemente una unidad administrativa. Fueron una realidad 
viva, creativa, hasta tal punto de que antes que Ronaldo Muñoz llevara a la teología el concepto de "Iglesia hogar", las comunidades de base vivían ya la "Iglesia hogar" como "una nueva manera de ser Iglesia marcada mucho por el estilo de la mujer". Las comunidades se van transformando así en una "instancia familiar"; la fe se encarna en una vivencia de la fraternidad que tiene sabores a té y pancito:

"Las mujeres generalmente se reunen y llevan su termito, o llevan cosas para preparar té y pancito o calzones rotos, cualquier dulce en fin, y siempre las reuniones son sirviéndose alguna cosita, o sea, los hombres no se preocupan de esas cosas, pero las mujeres si".

Hombres y mujeres comparten la fe, pero también la vida: vida y fe están indisoluble y espontáneamente unidas. La Iglesia doméstica empieza a coincidir con la Iglesia formal:

"Esta Iglesia que es acogida para todo el mundo y crea lazos de fraternidad en torno también a la mesa, no solamente en torno a la expresión de la fe, sino de compartir fraternos el pan y, también eso, compartiendo la vida, la vida de todos los dias porque las reuniones eran en las casas de las familias, entonces, es una manera de ir haciendo la Iglesia doméstica coincidir con la Iglesia formal, dijéramos asi".

Además, en las comunidades de base hombres y mujeres descubren un nuevo tipo de relación: una relación de hermanos, a pesar de que en una sociedad tan machista como la chilena no se podía concebir una relación hombre-mujer que escapara a la erotización ambiental y a la instrumentalización de la mujer como objeto de placer del hombre: "se sospecha siempre que detrás de una relación de hombre y mujer tiene que haber algo que tenga que ver con una relación sexual". En este sentido, las comunidades van a ser un espacio de humanización de la relación hombremujer: "en las comunidades se va a dar un esponjamiento en la relación y una experiencia de fraternidad muy linda". Hay un descubrimiento de la mujer como hermana por parte del hombre, y del hombre como hermano por parte de la mujer: "de poder mirarse a los ojos, de poder besarse y de poder tener una relación cariñosa pero en términos de fraternidad".

Otro aspecto importante de las comunidades de base es el redescubrir el Evangelio desde su realidad: "una descubre que la gente le pone la salsa de la vida y lo va aplicando a su propia realidad humana". De esta forma, se destacan elementos del Evangelio que para la vida del "pobre" son importantes, pero que son olvidados por las prédicas de los sacerdotes. Las palabras de Francisca Morales sobre la lectura del Evangelio por parte del pueblo son fundamentales para comprender cómo éste empieza a recuperar, a reapropiarse de un mensaje que tiene a los oprimidos y marginados como destinatarios principales y que, sin embargo, apenas había llegado a ellos 
puesto que había estado secularmente secuestrado por las interpretaciones de los que lo leían desde el poder o desde la ambigüedad, obteniendo como resultado una legitimación directa o encubierta de la injusticia:

"Para poder leer el Evangelio la gente necesita traer su manera, sus situaciones de vida, sus hechos de vida, que se llama formalmente, (...) para poder iluminar su vida con el Evangelio".

Y ese llevar la vida al comentario del Evangelio:

"... va dándole al Evangelio mismo una interpretación nueva a partir de la experiencia vital, cosa que generalmente en las prédicas no se da. Entonces, es muy rico este compartir en torno a la palabra. La Palabra empieza a ser redescubierta también por el pueblo".

Y en este proceso el pueblo se autodescubrirá como sujeto histórico capaz de transformar la realidad:

"La gente va teniendo acceso a una Palabra que tiene que ver con su vida directamente y que es novedosa porque va descubriendo como toda esta preferencia de Dios por el pobre, este actuar de Dios que de la debilidad se vale para hacer su obra, y que los pobres tienen capacidad, fuerza histórica no sólo para construir la Iglesia, sino también la sociedad".

Todo este descubrimiento, esa relación viva y eficaz entre Evangelio y vida, y decir vida era decir economía, política, cultura, estructura social, lleva consigo una radicalización de la presencia de los cristianos de base en las luchas por una sociedad más justa y fraterna, sin miseria ni opresión. Y en la lucha se encuentran, codo con codo, con todos aquellos que también luchan por la liberación, sean creyentes o no. Se produce un diálogo práctico entre cristianos y marxistas, por ejemplo, que rompe la tradicional barrera ideológica que hacía ver y creer que cristianismo y marxismo eran incompatibles. Muchos son los cristianos que descubren que entre cristianismo y marxismo no hay contradicción. Y lo descubren no desde la teoría, sino desde la praxis liberadora en las poblaciones, en las fábricas, en la universidad...

Todo este proceso de crecimiento de comunidades de base con una vivencia del Evangelio plenamente inserta en su vida cotidiana, en su compromiso activo por construir un mundo según los planes del Dios de Jesús de Nazaret (mundo de fraternidad, libertad, solidaridad, igualdad, justicica, alegría, paz), será avalado por el documento final de la Conferencia Episcopal Latinoamericana celebrada en Medellín en 1968. Hito histórico que recoge las experiencias que se estaban viviendo en el continente desde una perspectiva liberadora y que, después de analizar la situación de injusticia y violencia estructural que sufría América Latina, 
anima a continuar de forma enérgica los procesos de liberación, procesos en los que la Iglesia debe estar presente para ser realmente la "Iglesia de los pobres". Además, poco antes de celebrarse la II CELAM en Medellín, el 11 de agosto de 1968, un grupo de doscientos laicos, tres religiosas y siete sacerdotes tomaron la catedral de Santiago y colocaron una pancarta con el lema: "Por una Iglesia junto al pueblo y sus luchas". El hecho es indicativo de lo que se estaba descubriendo a raíz del impulso conciliar. Tomarse en serio el Vaticano II y Medellín llevará a muchos cristianos, de forma ineludible, a la acción sociopolítica como forma de transformar la realidad injusta. Y es a partir de aquí cuando la Iglesia oficial empezará a replegar su discurso. Pero el proceso estaba ya en marcha.

2. EL TRIENIO SOCLALISTA: LO MAS CERCANO AL REINO DE DIOS EN ESE MOMENTO ERA EL PROGRAMA DE LA UNIDAD POPULAR.

Muchos serán los cristianos que se implicarán en la lucha cotidiana por conseguir que la Unidad Popular llegara al poder. Unidad Popular que se presentaba como la opción política que más atención le prestaba a los más desfavorecidos de la sociedad. Además, tras el fracaso del gobierno democratacristiano de Frei, la vía socialista aparecía como la única viable para hacer una verdadera revolución en Chile. La proximidad de un régimen socialista motivó la reflexión de los cristianos. Antes de la elección de Allende, los agentes pastorales de la zona hicieron un discernimiento junto a Fernando Ariztía, obispo auxiliar de Santiago, contrastando los diferentes programas de los partidos políticos con el Evangelio y Medellín. En el grupo que estaba Francisca, formado por teólogos, pobladores, trabajadores y el propio Fernando Ariztía, llegaron a la conclusión de que las 40 medidas de la $\mathrm{UP}^{6}$ eran las que más coincidían con lo que ellos pensaban que era un caminar más cercano al Reino de Dios. No todos los agentes pastorales que participaron eran de izquierda, ni tampoco se intentó convencer a la gente de que votar a Allende era lo mejor. Lo más importante para ellos era que "votara por quien votara la gente viera las implicancias y la dimensión política de la fe; que no se puede votar al lote". Y tras las elecciones, por una cuestión de coherencia, se involucraron en el proyecto que el pueblo había elegido. Un proyecto que tenia en cuenta a los "pobres".

Hubo distintas maneras de participar de forma activa en el proyecto de la Unidad Popular una vez que ésta venció. Por un lado estaban los que lo hacían desde dentro de la coalición de izquierdas formando parte de alguno de los partidos implicados: Partido Comunista, Partido Socialista, MAPU, MIR, Izquierda Cristiana... pero otros, como es el caso de Francisca Morales, se insertaron en el trabajo gubernamental sin vincularle pertenencias partidistas, aunque sí la opción socialista como opción de liberación. Francisca nos lo relata así: 
"... tuvimos una experiencia como sentirnos que nuestro compromiso con los pobres era muy determinante y que no podíamos tener otro proyecto que el proyecto que tenía el pueblo pobre, que era más cercano al Evangelio también, entonces, nuestra opción fue clara al votar por Allende y después al participar, yo misma pedí permiso a la Congregación... Yo misma estaba trabajando, como te decía, estaba trabajando en la educación y pedí permiso, porque yo pertenecía al Departamento técnico del gremio de orientadores, para participar en un cargo a nivel de gobierno en el Equipo mixto de salud y educación para luchar contra las drogas y el alcoholismo. Entonces me dieron permiso y durante un año salí del liceo para trabajar con la gente del gobierno en la implementación de planes a nivel escolar contra las drogas y contra el alcoholismo. Esto fue para mi un año de gran enriquecimiento, $y$ además de contacto con gente no creyente trabajando en una misma situación. Fue realmente muy lindo el trabajo que hicimos. Duró un año. Muy interesante. Pero, digamos, esta postura de desbloqueo que se habia producido en uno frente a los hermanos no creyentes te hacía participar, entonces yo trabajé a nivel de gobierno y una hermana de Congregación, una hermana que es abogada, (...) ella trabajaba en la JAP en su población, estaba a cargo de conseguir harina de los molinos para las panaderias para el pan de la población. Entonces, era como normal, casi todos nosotros participábamos de las organizaciones poblacionales o en instancias gubernamentales de trabajo popular, digamos, en alfabetización, por ejemplo, había hermanas de mi Congregación que participaban en tiempos de Allende en alfabetización. No sólo de mi congregación, de otras congregaciones también. Habia toda una efervescencia de compromiso".

Efervescencia de compromiso que, para los cristianos de base, estaba avalada por el Vaticano II, por Medellín y por la naciente teología latinoamericana de la liberación, además de por la experiencia del movimiento Cristianos por el Socialismo (CpS).

Respecto a la teología de la liberación, Francisca comenta: "yo creo que la teología de la liberación nos dio un peso de fe y de reflexión capaz de hacer el salto de una Iglesia más encerrada en su evangelización más directa, a esta preocupación por el bien común más global de la sociedad". Era, y es, una teología que superaba lo intraeclesial y se abría al Mundo tal como lo había dicho el Concilio.

Por su parte, $\mathrm{CpS}$ fue un movimiento que nació como un grupo sacerdotal, grupo de "los ochenta", a partir de una jornada de estudio que varios sacerdotes, insertos en las poblaciones marginales de Santiago y con inquietudes por conocer a Marx y el marxismo, habían organizado para analizar el rol de los cristianos en la construcción del socialismo. Meses 
más tarde, en septiembre de 1971 (la jornada de reflexión había sido en abril de 1971), nacía Cristianos por el Socialismo a partir del grupo nuclear de "los ochenta" (grupo que se llamó así porque ochenta sacerdotes habían firmado una Declaración tras la jornada de abril en la que decían, entre otras cosas, que entre cristianismo y socialismo no había contradicción y que "ser cristiano es ser solidario. Ser solidario en estos momentos' en Chile es participar en el proyecto histórico que su pueblo se ha trazado"7).

La historia de Cristianos por el Socialismo es una historia que a menudo se ha reducido a la historia de la élite dirigente, por lo que se ha reducido la experiencia a un arrebato vanguardista de caracter sectario liderado por sacerdotes marxistas que pretendían combatir el maridaje de la Iglesia católica con la cultura burguesa y, en ese empeño, se dogmatizaron y lo que empezó siendo un acompañamiento crítico de la construcción del socialismo en Chile, acabó siendo un apoyo acrítico a la UP que rozó el confesionalismo de izquierdas. Es cierto que parte de esto ocurrió, pero no se puede generalizar y convertir una experiencia tan compleja y rica en sólo eso. Fue más, mucho más. Y posiblemente lo más jugoso del movimiento no se desarrolló en la cúpula sacerdotal sino en las bases populares, en donde el movimiento se llenó de laicos y religiosas. Desde esta perspectiva el testimonio de Francisca Morales es muy importante para recuperar la historia de Cristianos por el Socialismo más allá de la visión reduccionista de sus detractores, para los que todo fueron errores (ésta es la visión de la Iglesia oficial, por ejemplo, especialmente marcada por la insubordinación de los sacerdotes de Cristianos por el Socialismo; trauma que todavía hoy no acaba de procesar).

Francisca Morales, que vivió la experiencia en la periferia (periferia geográfica: una población marginal, y periferia respecto al centro dirigente del movimiento), siente que $\mathrm{CpS}$ "fue un grupo muy importante que nos ayudó a muchos sacerdotes y religiosas a entender la fe con los ojos de los pobres, a vivir una inserción más lucida en el mundo de los pobres". Hasta ese momento la cercanía de la vida religiosa y de la Iglesia en general era una cercanía desde arriba, "dando cosas, socorriendo, siendo bastante samaritana", pero no había sido una Iglesia formada ni por pobres ni por agentes pastorales que vieran la vida "desde'el mundo de opresión $e$ injusticia en que vive el pobre". Así que fue $\mathrm{CpS}$ lo que le ayudó a articular la oposición que había entre estructura social y Reino de Dios y a "articular mejor una fe que se comprometía en la transformación de esta sociedad, que preparaba el Reino preparando el pais también". En el contexto, al que hemos hecho referencia, de trabajo en las organizaciones poblacionales o en las instancias gubernamentales de trabajo popular (alfabetización, programas contra la droga y el alcoholismo...), CpS les proporcionaba un marco de referencia que les daba una mística y una serie de análisis de coyuntura útiles para comprender la complejidad del entramado social. 
Francisca Morales valora como negativa la implicación de sacerdotes y religiosas en partidos políticos de forma directa, y apunta que muchos creyeron que todo el movimiento estaba implicado en partidos políticos: " $y$ la verdad es que habia mucha gente que no participaba en los partidos políticos". Lo que sí tenían claro era la opción de izquierda y por el socialismo, pero la vinculación orgánica a los partidos (MIR, MAPU, PC, PS) sólo la tenían algunos miembros.

Francisca Morales añade que para ella y para otros que llevaban varios años viviendo en la población todo eso, CpS y la teología de la liberación que estaba en efervescencia, les proporcionaba las respuestas a todas las inquietudes que habían ido acumulando al convivir con los pobres. Cuando ella llegó a la población el cambio respecto al lugar de donde venía, clase media profesional, fue brutal. A los dos años de estar en la población llegó a enfermar al tomar conciencia de la gravedad de la injusticia:

"... yo me llegué a enfermar a los dos años de vivir en la población, te digo, al tomar conciencia de la gravedad de la injusticia y que ésta forma parte de una estructura, que no es una cuestión casual, ni flojera de los pobres, ni por falta de educación. También la falta de educación es injusticia, pero, jcómo decirtel, eran cosas estructurales que tenian incidencias, ipero tan brutales!, en la vida de los pobres. Entonces, todo se te va iluminando: las cosas que aprendiste, que estudiaste, y también te vas asustando porque te empieza a dar vuelta todo, ;claro!, desde el punto de vista teológico como desde el punto de vista sociopolítico. Empiezas a ver las cosas al revés (...); después de dos años varios de nosotros sufrimos esta situación porque no es capaz de absorber con equilibrio tanto sufrimiento, sobre todo si tú te metes mucho en la vida de la gente y vas participando de todas sus dificultades y cosas. Sientes una impotencia tan grande, una tensión, una angustia, y te vas sintiendo incomunicada con el mundo de los ricos también. Incluso con hermanas de la propia Congregación que trabajan en otro ambiente; que tensa mucho porque tu perspectiva cambió diametralmente. Empezar a sentir con el corazón y los ojos de los pobres es otra cosa".

Y desde ahí descubrió que "la gente tiene una práctica de fe que no está expresada en manuales de catecismo, pero una práctica de fe mucho más lógica desde el punto de vista humano que lo que tú has aprendido en montones de cosas". Y Francisca agrega que mirar el mundo desde la experiencia de los "pobres" "es muy abrumador", pero también te abre a toda la riqueza de su fe, y que no todo es "error doctrinal o ignorancia, o religiosidad popular con deformaciones". La gente sencilla vive cotidianamente valores muy importantes del Evangelio: "una libertad evangélica para vivir la solidaridad que es impresionante; una confianza 
activa en la Providencia; una manera de responder a los requerimientos del amor fraterno...".

En definitiva, sobre CpS Francisca concluye que ayudó a iluminar toda esa experiencia: que es verdad que algunos de una forma infantil se entusiasmaron políticamente, pero eso no quita lo positivo que tuvo en cuanto a una espiritualidad de raigambre bíblica que avalaba, fortalecía y daba sentido a esa experiencia de compromiso y vida entre los pobres.

\section{RESISTIR A PINOCHET: LAS MUJERES SALEN DE LA INVISIBILIDAD.}

El 11 de septiembre de 1973 el golpe de estado capitaneado por Augusto Pinochet abortaba el intento chileno de llegar al socialismo a través de la democracia. A partir de ese momento se desplegó toda una estrategia basada en el terror cuyos objetivos eran descabezar y desarticular el movimiento popular y los partidos de la Unidad Popular, por un lado, y poner las bases de un régimen fundacional que arrancara de cuajo cualquier posibilidad de retorno a la utopía socialista, por otro. La represión política (asesinatos, torturas, violaciones, desparecimientos...) y la represión económica (hambre, cesantía, salarios de miseria...) aseguró que el neoliberalismo fuera implantado en Chile sin oposición. La única capacidad de resistencia que pudo organizarse en esos momentos se orientó a salvar las vidas de los perseguidos y más tarde a defender a las víctimas de violaciones de los. Derechos Humanos. Esta defensa se canalizó primero a través del Comité de Cooperación para la Paz en Chile, que nació el 6 de octubre de 1973 y tenía una composición y organización ecuménica, y, tras ser disuelto éste a finales de 1975 por presiones de Pinochet hacia el cardenal Silva, en enero de 1976, como continuación del mismo pero con un carácter específicamente católico, la Vicaría de la Solidaridad. Tanto en uno como en otra van a tener un rol destacado muchos de los militantes que habían luchado a favor del socialismo de la Unidad Popular y que ahora, por imperativo de la nueva situación, habían dejado aparcados los conflictos más ideológicos, habían cerrado filas tras la jerarquía católica, única institución que conservaba cierta autonomía tras el golpe, y se habían puesto manos a la obra en la tarea de organizar la asistencia de los perseguidos.

"Yo creo que si no hubiese habido ya un caminar de Iglesia de base con presencia de sacerdotes, de religiosas y de laicos, de cierto caminar digamos, habría sido muy dificil articular todo lo que se articuló en el primer momento del golpe, porque en el primer momento del golpe se organizó casi espontáneamente una red de gente que empezó a arriesgar el pellejo por salvar la vida de la gente, a tener en sus casa gente, a llevarla a las embajadas, a servir de vinculación para poder salvar vidas de acá y allá, y con el obispo 
a la cabeza se produjo esta situación, cuando estaba don Fernando Ariztía en la zona Oeste y él fue el primero que empezó a llevar gente a la embajada, antes de que existiera el Comité de la Paz ni Vicaría de la Solidaridad, cuando recién empezó. Después de eso empezó la ACNUR pero, el ACNUR a tomar la cosa de los refugiados, pero lo primero que hubo fue esta cosa casi espontánea, y muy seria y muy rigurosa también, de darnos cuenta que, bueno, yo creo que la mayoría de los sacerdotes y religiosas que viviamos en poblaciones habíamos participado un poco en la dimensión más política, en una vivencia de una fe más politizada digamos, en cierto sentido, desde la época de Allende".

Poco a poco su labor pasará de lo meramente asistencial a lo promocional, ayudando a articular la supervivencia en las poblaciones. Como escribía Pablo Fontaine, sacerdote de los Sagrados Corazones que perteneció de forma crítica al movimiento Cristianos por el Socialismo: "... exagerando un poco, parecería, por ejemplo, que no es tanto la parroquia la que está en la población, sino la población la que trata de entrar a la Iglesia". ${ }^{8}$ La Iglesia católica se convirtió en una especie de alero bajo el que se fue fraguando la recomposición de la organización popular.

Una de las características de este momento, en lo que se refiere a los actores que organizaron la resistencia a la dictadura, fue la aparición de "nuevos" sujetos que se implicaron radicalmente en la defensa de los Derechos Humanos y en la organización de la supervivencia. Los sujetos más protagónicos durante los años anteriores, o cayeron víctimas de la represión militar o tuvieron que exiliarse, por lo que el testigo fue tomado por otras muchas personas que también habían participado en las luchas de liberación del pueblo pero desde un compromiso cotidiano y anónimo, o por personas que toman por primera vez un compromiso más activo $y$ enérgico ante la urgencia del momento. Y dentro de esa gente anónima que se implica en la defensa de los Derechos Humanos y mantiene en pie los pilares organizativos de la supervivencia hay que destacar el rol funadamental de las mujeres. Mujeres que salen de la invisibilidad y toman las riendas de la oposición a la dictadura y de la lucha por la vida. Todo el potencial organizativo de resistencia y creatividad de las mujeres chilenas emerge en estos años. Francisca lo relata así:

"... la lucha de las mujeres fue la lucha organizada primera que se dio en Chile contra la dictadura y a favor de los Derechos Humanos, $y$ en estas organizaciones participaban moros y cristianos, por una manera de decir, gente creyente y no creyente. Pero la Iglesia se fue enriqueciendo por esta participación en la lucha por la justicia y por la presencia de mujeres muy líderes en toda la línea de la solidaridad, tanto en la participación en organizaciones $y$ movimientos contra la dictadura como en cosas de supervivencia. Toda la situación de pobreza, de cesantía que se dio hizo 
rápidamente aflorar comedores infantiles, ollas familiares, ollas comunes, y alli la presencia de la mujer era determinante".

Las mujeres asumen la responsabilidad de mantener la subsistencia de la casa mientras que la mayoría de los hombres se vienen abajo como consecuencia de una concepción machista de los roles sociales, en la cual el hombre vale en la medida en que puede trabajar para mantener su hogar:

"Los hombres cuando quedan cesantes como que pierden la razón de vivir casi, no se descubren como que valen si no son capaces de aportar para la olla común, decimos aqui en Chile. Entonces casi siempre los hombres se deprimen y se avergüenzan mucho de tener que ir' a buscar comida fuera de casa para su hogar cuando él ha sido capaz de mantener el hogar, y se sienten con las manos cortadas por la cesantia. Entonces ahi las mujeres tuvieron un papel muy importante que ayudó también a los hombres a tomar conciencia".

Y Francisca Morales añade este ejemplo:

"Para los primeros de mayo que empezamos a protestar con la dictadura y a reclamar justicia para el mundo de los pobres, las mujeres tuvieron un papel muy importante. En una de las concentraciones Clotario Blest, un dirigente sindical muy cristiano, retó a los hombres ¿verdad?, y les dijo que estaban como gallinas escondidas, que el primero de mayo era el día de los trabajadores y nada más que había mujeres, y mujeres trabajadoras y mujeres amas de casa y niños, pero no hombres".

Y junto a la organización de la supervivencia al alero de las instituciones de la Iglesia católica, también fue resurgiendo la voz profética de las comunidades de base: voz que iba más allá de la denuncia de las violaciones de los Derechos Humanos y denunciaba el sistema impuesto en su totalidad. Sistema neoliberal levantado con sangre y terror. La violación de los Derechos Humanos era sólo una consecuencia del nuevo orden, por lo que no bastaba con tener una actitud de Iglesia samaritana que recogiera al herido en el camino y curara sus heridas, sino también era necesario y urgente una actitud de Iglesia profética que denunciara el sistema de muerte y anunciara, con la palabra y el gesto, una sociedad donde la liberación de las opresiones, represiones y exclusiones fuera una realidad. $\mathrm{Y}$ 'ese talante profético se fortalecerá en las comunidades de base, menos mediatizadas que la Iglesia jerárquica por la tradicional diplomacia (léase ambigüedad) eclesiástica y su postura de no romper con el poder. Sobre el aporte de las mujeres, Francisca nos dice:

"Y la verdad es que en todo ese mundo de mujeres luchadoras, la mujer cristiana también estaba metida y la gente de las comunidades, fundamentalmente. Por eso que las comunidades cristianas en Chile 
tuvieron esa marca como de profetismo, de capacidad de jugarse por la lucha de los Derechos Humanos (...). La participación de las mujeres fue muy determinante, y eso enriqueció la vida de la Iglesia también y son muchas las que participan en la Iglesia, entonces, fue dándole también a la Iglesia ese carácter de Iglesia solidaria, de Iglesia samaritana, de Iglesia profética. Bueno, yo no digo que todo fuera tarea de las mujeres iverdad?, pero creo que en Chile hubo una presencia de las mujeres muy determinante. Fue como el primer frente de lucha. Los hombres fueron apareciendo después, y sobre todo los jóvenes fueron tomando las banderas de la lucha. Pero tú tienes movimientos como el 'Sebastián Acevedo' en que habia muchisimas mujeres participando, y todo lo que era la lucha por la vida, mujeres por la vida. Las mujeres fuimos capaces de juntarnos más allá de las ideologías para luchar por la vida".

Precisamente uno de los movimientos más importantes en lo que supuso de denuncia y desenmascaramiento de los mecanismos represivos del régimen militar fue el Movimiento Contra la Tortura "Sebastián Acevedo". Su estrategia consistía en señalar públicamente los centros de tortura que existían en Santiago. El nombre del movimiento mantenía viva la memoria de Sebastián Acevedo, minero del carbón, que se prendió fuego ante la catedral de Concepción como protesta por las torturas a las que la CNI (Central Nacional de Información) estaba sometiendo a sus hijos (un hijo de veintidós años y una hija de veinte). A partir de la indignación ética ante la tortura, un grupo de laicos, religiosas y sacerdotes crearon en 1983 este movimiento de protesta pública que utilizará métodos no-violentos pero más confrontacionales con el régimen militar que los utilizados por la Vicaría de la Solidaridad. Como apunta uno de sus miembros, el movimiento "creaba resistencia al régimen, pero la Vicaría (de la Solidaridad) no"."

Además, en este campo de la denuncia profética, no podemos olvidar el papel tan importante que jugó la Coordinadora de Comunidades Cristianas Populares, que empezó a funcionar a partir de 1979. La Coordinadora pretendía servir de aglutinante de las experiencias comunitarias de base que se vivían con un mayor compromiso político. La Coordinadora, desde sus primeros pasos, fue una instancia que quería estar al servicio de las comunidades cristianas populares, tanto a nivel de reflexión como a nivel de la organización de actos que pudieran aunar a las comunidades en manifestaciones colectivas de fe en el Dios de la vida frente al sistema de muerte que existía en Chile. Dos de sus expresiones más importantes fueron los Vía Crucis populares y los Encuentros anuales.

"Estuve participando con mi comunidad, con las comunidades en las que yo estaba, en todas las cosas de la coordinación de las comunidades. Pero no tuve vínculo de dirección. (La Coordinadora) Buena instancia laical, eclesial, que tuvo un papel muy importante 
para darle a las comunidades esta dimensión profética. Todos los Vía Crucis que. se organizaban, por ejemplo, yo participé con la comunidad eclesial, con toda la gente. Participé todos los años en el Vía Crucis y era cosa muy, muy importante. Muy importante en que la Iglesia se hacía presente actualizando la pasión de Cristo con toda la realidad sufriente del momento, con unas estaciones bien preparadas por cada coordinación de zona, y realmente una palabra profética, interpelante, fuerte. $Y$ en ese tiempo las comunidades de la Coordinadora, especialmente, teníamos otros eventos, otras cosas que se organizaban para lo de monseñor Romero, en fin, para... bueno, participábamos en muchísisimas cosas contra la dictadura y también habia jornadas de reflexión y de formación. $Y$ los laicos fueron tomaindo como más estatura dentro de la Iglesia".

Ahora bien, el gran pecado de la Coordinadora fue su autonomía. La Iglesia oficial no estaba dispuesta, y mucho menos después de la experiencia de Cristianos por el Socialismo, a dar su beneplácito a una Coordinadora que, según su punto de vista, asumía espacios que pertenecían a la jerarquía, tales como convocar actos públicos de carácter religioso o dar directrices pastorales. Sin embargo, no creó ninguna instancia con las características de la Coordinadora, al menos en los años duros de persecución, aunque sí lo hizo en 1986 al crear el Area CEB (Area de Comunidades Eclesiales de Base), tras lo cual pidió la disolución de la Coordinadora, puesto que ya existía un organismo oficial que se encargaría de la coordinación de comunidades de base. Como dice Francisca Morales:

"Ahora, fricciones que se produjeron con la jerarquía, yo creo que hubo responsabilidad de lado y lado. La jerarquía demasiado celosa de su autoridad y las comunidades de laicos también muy celosos de mantener su espacio y libertad para organizar dentro de la Iglesia cosas".

Dos cuestiones que estuvieron presentes mientras existió la Coordinadora fue la de la representatividad: ia quienes representaba realmente?, y la de la politización. Sobre la primera:

"Yo creo que nuestra gente es bien especial, o sea, siempre hay gente, nosotros decimos los más puntúos, siempre hay gente que tiene como más clara esta dimensión profética de la vida cristiana y que tiene más compromiso también en esa línea y que responde más a esto, y hay siempre gente temerosa, miedosa. $Y$ en nuestras comunidades hay de todo. Las comunidades de base hacen el milagro de juntar gentes de distintas tendencias, de distintas eclesiologías, jahora!, todo depende de la conducción parroquial, la línea que se va asumiendo (...). Yo diría que no hay una gran separación, lo que pasa es que no todas las comunidades en su totalidad se han sentido 
representadas en la coordinación, algunos dicen que era la pura cúpula de las comunidades...".

Y sobre la segunda, Francisca señala que la politización de la Coordinadora no implicaba necesariamente una partidización de la postura. No se hacía política partidista, sino un posicionarse críticamente frente a la dictadura:

"Depende un poco de lo que tú entiendes por política. Si por política se entiende la preocupación por la coyuntura nacional, yo creo que sí. Pero de alli a que toda la gente estuviera en una línea de partido, no me parece".

No tenemos espacio para profundizar en estas dos cuestiones, que estarán continuamente en la palestra, pero lo que sí queremos apuntar es que ambas fueron utilizadas para desautorizar las acciones de la Coordinadora por parte de sus detractores. Sin embargo, la Coordinadora siempre tuvo claro que su papel no era ser un organismo que coordinara toda la vida de todas las comunidades, sino ser la catalizadora del talante profético de las comunidades más comprometidas en la lucha contra la dictadura, lucha que forzosamente era una lucha política sin que por ello implicara una partidización concreta de la Coordinadora como Coordinadora, aunque tampoco, como es lógico, la exclusión de las legítimas opciones partidistas que cada cristiano podía tener a nivel personal. Sin duda las comunidades cristianas populares fueron una de las instancias más críticas y combativas durante los años de dictadura militar. $\mathrm{Y}$ además influyeron mucho en la "conversión" de los propios religiosos que las acompañaban:

"Además, las comunidades cristianas populares nos ayudaron a los religiosos a asumir nuestro propio carisma profético, de compromiso con el pueblo de mejor forma. También marcaron estilo de liturgia, de oración. Era muy pedagógico todo lo que se hacía. Entonces, todo eso iluminaba la vida eclesial normal en cada lugar. La vida corriente estaba iluminada por esas experiencias de Dios y de fe, de expresión de vida, de fe comunitaria, que daba como libertad para introducir en la liturgia, en nuestras propias celebraciones de casa, como quien dijera, elementos así de la vida, la simbología, todo eso. Yo creo que fue un mutuo alimentarse".

\section{A MODO DE EPILOGO: APUNTES SOBRE LA TRANSICION}

En 1990, después de 17 años de resistencia frente a la dictadura militar, llegaba el tan ansiado camino hacia la democracia. Sin embargo ha bastado el inicio de la transición para ver que entre la democracia "pactada" 
que se ha conseguido y la democracia real, del pueblo, que muchos buscaron y por la que arriesgaron sus vidas enfrentándose a la dictadura hay una distancia muy amplia: la distancia de 17 años implantando y desarrollando el neoliberalismo de forma desenfrenada. Además, la sombra de Pinochet sigue presente. No es éste lugar para extendernos. Sólo queremos retratar con algunas pinceladas, a partir del testimonio de Francisca Morales, hasta qué punto el neoliberalismo es un sistema que quita la vida en lo más cotidiano.

"Yo creo que toda la situación del país está mal, en el sentido de que no hay como interés, hay cierto cansancio, y cierta apatía y cierta indiferencia y, además, hay una sociedad de consumo que nos ha metido el consumo a través de la tele y la mentalidad consumista, individualista, en las casas, a través de la televisión también en el mundo popular. Hay poca participación social en el mundo popular (...), en general la organización popular, digamos, está muy disminuida, en el mundo del trabajo está muy atomizada, y en el mundo popular la gente como que no cree, no cree en las promesas, hay mucho desencanto después de tantos años de lucha en la dictadura. La transición democrática la gente no la siente ni mucha transición, ni muy democrática, porque el modelo neoliberal ha permitido que sigan acumulando los que tienen plata y que sigan empobreciéndose los que están pobres. No ha habido un cambio radical en la cuestión del trabajo, en el plan laboral..., hay muchos subterfugios que permiten que se explote y sobre-explote a la gente (...). Como cuesta mantenerse en el trabajo, la gente acepta cualquier cosa, no contratan nuevo personal para trabajo extra y le obligan, le ofrecen, pero en el fondo obligan a la gente a trabajar horas extraordinarias y la gente lo acepta porque, entonces, aumenta su plata y eso le permite ir pagando las deudas, que la gente con la cosa del consumo va comprando con las tarjetas, o se va endeudando, $y$ entonces vive en el fondo ahogado $y$ asfixiado por las deudas $y$ cansado por el exceso de trabajo (...). Hay una situación de empobrecimiento y de bajos salarios muy, muy grande. De mucha explotación".

Y junto al neoliberalismo estructural y cotidiano, el repliegue de la Iglesia católica hacia sí misma. Repliegue que ya empezó en los años ochenta y que sigue en marcha desoyendo lo fundamental del "aggiormanento" del Vaticano II.

"Ahora yo siento que el ritmo de renovación y de cambio ha sido frenado en cierto sentido... Hubo un momento en que la vida en las poblaciones fue una tendencia a la inserción muy fuerte. Yo así lo percibo, como que la vida religiosa perdió el impulso de la renovación conciliar primera. Ese ritmo más acelerado de cambio se ha frenado y, por lo tanto, también se ha empezado como a legitimar 
el valor de las instituciones que tiene la vida religiosa, el papel de la educación, todo eso, entonces, la gente ya dice 'da lo mismo estar, depende de las vocaciones', cuando antes era como haber descubierto, haber redescubierto el carisma original de la vida religiosa y darles un sentido como más de novedad, como aporte a la Iglesia. El carisma de la vida religiosa tendría que dar un aporte permanente, abriendo caminos nuevos, dispuestos a avanzar. Entonces, estar en el mundo de los pobres era eso, ir como descubriendo un mundo nuevo donde la Iglesia tenía que hacerse presente de una manera distinta. $Y$ eso se ha frenado desgraciadamente... La otra cosa que es como sintomático en este tiempo es... la formación definitivamente se dejó de tener en la población. Pero yo siento que la vida religiosa va hasta donde los pastores dicen. No se quiere dar un paso de riesgo más allá (...), entonces, también toda la metida de la vida religiosa y pastoral en el mundo más social ha disminuido".

En fin, sólo reiterar brevemente la necesidad de recuperar la voz de los que no tienen poder para reconstruir con fidelidad, no exenta de complejidades, la historia de hombres y mujeres. En este caso se ha tratado del testimonio de una religiosa que optó por hacerse pobre junto a los pobres. Quedan muchos otros por escuchar, aguzando el oído para sacar de los susurros esa historia que no está en la historia pero que sin embargo es la que configura la historia más verdadera, la de la vida. Si la historia no amplifica la voz de los que no tienen poder, no es historia, es sólo un panfleto al servicio de los poderosos. Hasta aquí este acercamiento a la historia de la Iglesia de base chilena desde la perspectiva de una mujer que tiene voz propia y ha comprometido su vida para que otras también la tengan.

\section{NOTAS:}

1 Francisca Morales, Testimonio oral, Santiago, Chile, 3/12/93.

2 En Chile las comunidades de base existían ya desde finales de los años cincuenta. No es un invento de la Misión General, aunque bien es verdad que ésta las impulsó de manera más generalizada. El origen de las comunidades de base fueron los grupos bíblicos que, como nos dice Segundo Galilea (Testimonio oral, Santiago, Chile, 24/11/93): "eran comunidades de base pero en torno a la Biblia, sumamente religiosos: rezaban, leian la Biblia. Eran de base parroquial". En sus inicios las comunidades de base empezaron a aflorar a partir de una decisión institucional: las parroquias eran cada vez más extensas y se hacía necesario descentralizar las funciones y responsabilidades. Fruto de esa determinación empezarán a aparecer las capillas populares. 
3 Los entrecomillados, a no ser que indiquemos lo contrario, pertenecen al Testimonio oral de Francisca Morales (Santiago, Chile, 3/12/93).

4 El "Hogar de Cristo" fue la última obra del jesuita Alberto Hurtado. Surgió después de descubrir que los niños que pedían limosna durante la mañana, se refugiaban debajo de los puentes del Mapocho para pasar la noche. Tras ese descubrimiento Alberto Hurtado buscó la manera de conseguir una habitación donde pudieran alojarse dignamente. Éste es el origen de una obra de caridad que se ha extendido por todo Chile con el nombre de "Hogar de Cristo".

5 Sergio Silva, Testimonio oral, Santiago, Chile, 3/11/93. El informante es sacerdote de la Congregación de los Sagrados Corazones. En el momento de la entrevista era Vicedecano de la Facultad de Teología de la Universidad Católica de Santiago de Chile. Actualmente es su Decano.

6 El Programa de gobierno de la UP contenía amplias medidas económicas y sociales encaminadas a superar la miseria y construir una sociedad sin los desequilibrios socioeconómicos que existían en Chile. Pretendían acabar "con el poder del capital monopolista nacional y extranjero $y$ del latifundio", que conllevaba la expropiación y nacionalización de las riquezas básicas y actividades fundamentales de Chile que estaban en manos de capitales extranjeros o monopolios internos: la gran minería (cobre, salitre, yodo, hierro y carbón mineral); el sistema financiero (banca privada y seguros); el comercio exterior; las grandes empresas y monopolios de distribución; monopolios industriales estratégicos; y en general toda actividad que condiciona el desarrollo económico y social del país (transportes, petróleo, energía eléctrica, siderurgia...). Además de profundizar la reforma agraria y toda una serie de medidas sociales que dignificaran la vida del pueblo chileno: viviendas, trabajo estable, salarios suficientes, atención médica, escuelas y universidades, agua potable, alcantarillado, alumbrado público, calles y aceras pavimentadas, teléfonos, canchas deportivas, turismo y balnearios populares... Datos del "Programa básico de Gobierno de la Unidad Popular", en H. Godoy, Estructura social de Chile, Santiago, Chile, 1971, ps. 562-581.

7 Los ochenta, Declaración (abril 1971)., "Pastoral Popular" n¹23 (Santiago, Chile, mayo-junio 1971), p. 51.

$8 \quad$ P. Fontaine, Liberación y organizaciones populares, en AA.VV., La Iglesia de los pobres en América Latina. Antología, Santiago, Chile, 1983 , p. 347.

9 José Aldunate, Testimonio oral, Santiago, Chile, 25/11/93. 